\title{
Do attitudes, intentions and actions of school food coordinators regarding public organic food procurement policy improve the eating environment at school? Results from the iPOPY study
}

\author{
Chen He* , Federico JA Perez-Cueto and Bent E Mikkelsen \\ Research Group for Meal Science \& Public Health Nutrition, Aalborg University Copenhagen, A.C. Meyers \\ Vaenge 15, Copenhagen 2450, 2750 Ballerup, Denmark
}

Submitted 25 June 2012: Final revision received 27 February 2013: Accepted 24 April 2013: First published online 31 May 2013

\begin{abstract}
Objective: The present study investigates whether public organic food procurement policies have the potential to induce changes in the school food service environment.

Design: A comparative cross-national survey was conducted in public primary and/or secondary schools in Finland, Germany and Italy. The school food coordinators completed a web-based questionnaire on their attitudes, intentions and actions towards organic school food provision.

Setting: In Germany, 122 out of 2050 schools in the state of Hesse responded. In Finland, 250 out of 998 schools across the country responded. In Italy, 215 out of 940 schools from eight provinces responded.

Subjects: School food coordinators in the sample of schools in the three countries. Results: The German and Finnish school food coordinators separately most agreed with the promotion of healthy eating habits $(P<0 \cdot 001)$ and organic food $(P<0 \cdot 001)$ by schools. The Finnish schools were most likely to adopt a food and nutrition policy $(P<0 \cdot 001)$, a health-promoting school policy according to WHO principles $(P<0 \cdot 001)$, to have a playground $(P<0 \cdot 001)$, to involve physical activity themes in teaching $(P=0 \cdot 012)$ and to have a canteen $(P<0 \cdot 001)$. The Italian schools were most likely to involve the food and nutrition policy in pedagogical activities $(P=0 \cdot 004)$, to serve nutritional school meals $(P<0 \cdot 001)$ and to recommend children to eat healthily $(P<0 \cdot 001)$. In the three countries, the non-organic schools were less likely to adopt a food and nutrition policy $(P<0 \cdot 001)$, a WHO health-promoting policy $(P<0 \cdot 001)$ and have a canteen $(P=0 \cdot 017)$ than the organic schools.

Conclusions: The study suggests that there is a gap in the effects of public organic food procurement policy on building a healthier school food environment.
\end{abstract}

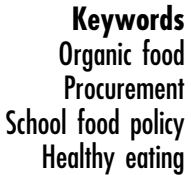

Organic food Procurement Healthy eating
Public-sector food procurement can play a key role in providing healthy, sustainable food to the public ${ }^{(1,2)}$. Including organic food that often is seen to represent sustainability in public procurement represents opportunities and challenges when implementing policy into practice ${ }^{(3-5)}$. On the one hand, organic food in public procurement could contribute to improved health awareness, environmentfriendly issues and might encourage small local business to support sustainable development ${ }^{(6,7)}$. On the other hand, one important factor is the increased cost of buying organic food compared with non-organic food, which may present a much greater challenge than when providing only non-organic meals ${ }^{(8)}$.

Recent years have seen many countries utilizing new, healthier diet strategies and policies that aim to create a healthy food environment at public sectors such as school $^{(9-12)}$. Many studies indicate that promoting healthy eating habits among children in schools could be a promising approach to counteracting the increasing prevalence of childhood overweight and obesity ${ }^{(13-16)}$. Previous studies also show that increasing the availability of healthier foods as part of school meals results in their increased consumption by children ${ }^{(10,17,18)}$. It is therefore relevant to study whether there is mutual influence and positive relationship between the introduction of organic supply policies and healthier eating environments at school.

The present study was part of the CORE Research Pilot Project, innovative Public Organic food Procurement for Youth (iPOPY). The project was carried out in countries where school food is a part of the public welfare provision (the citizenship model) ${ }^{(19)}$ as well as in countries where it is offered on the basis of a market-oriented model $^{(20)}$. An example of the citizenship model is found 
in Finland, where a prepared free school lunch is served as part of the welfare system ${ }^{(19,21)}$. The concept of Finnish school lunch is to offer nutritional and varied meals to pupils. At the same time, the school meal is also used as a pedagogical tool to teach nutrition topics and to advocate for healthier diets ${ }^{(21-23)}$. In Germany, where school meals have a market-oriented model, the only kind of school food provision is a complementary between-meals snack rather than full meals. Furthermore, there is no federal compulsory regulation to implement a school meal programme and consequently only a small proportion of schools offer school meals ${ }^{(24-26)}$. In Italy, the school meals represent a mix of citizenship and market-oriented models. This means that in some regions school meals are organized with a differential price, where parents with higher incomes pay more than those with lower incomes ${ }^{(4,27)}$. The Italian school food service is not recognized simply for the provision of meals for children or good nutrition education, but is also seen as a method of sustainable food procurement ${ }^{(27)}$. Moreover, Finland, Germany and Italy are also geographic representatives of northern, middle and southern Europe.

The present study is based on the Theory of Planned Behaviour (TPB) ${ }^{(28)}$ and employed a modified TPB as a theoretical framework to investigate schools' individual attitudes and policies towards organic foods. The modified TPB was interested in investigating the effect that actions (behaviours) are preceded by attitudes and intentions ${ }^{(29)}$. In turn, attitude has a strong association with intention and action in multiple contexts ${ }^{(29)}$. Since it is not possible to measure a school's attitude, intention and action, the study builds on the assumption that there is one important stakeholder within the school environment: the school food coordinator (SFC). It analyses the interplay between the different levels of attitudes, intentions (policies) and actions among SFCs and the interplay between the two school food trajectories: organic sourcing and healthy eating. The aim of the study was to investigate the relationship between public organic food procurement policy and SFCs' attitudinal issues, intentions and actions in relation to the school meals system and whether such policies lead to the promotion of a healthier school food environment.

\section{Experimental methods}

\section{Study design and participants}

A comparative cross-national survey was conducted between November 2009 and April 2010. A self-administered web-based questionnaire (WBQ) was completed by the SFCs in selected public primary and/or lower secondary schools (children aged 6-15 years) in Finland, Germany and Italy. Since schools at a collective level are difficult to measure, it was decided to use SFCs as the research subjects as they can be identified as individuals, but can also provide a holistic view of the school food situation at a collective level.
SFCs in the present study refer to school staff in charge of the school food service. In practice, this person could be anyone from the school headmaster to a school food caterer. Schools were divided into two categories: (i) organic schools that had an organic sourcing policy aimed at having a certain amount of organic ingredients in school meals; and (ii) nonorganic schools that had no policy on such an issue, using only non-organic ingredients. The classification was done based on the survey responses since it was not possible to decide a priori whether the schools in the sample were organic or non-organic schools. A convenience sampling approach was used to select participating schools. The selected schools were sampled and contacted through iPOPY researchers' networks.

The study first explored the attitudes of the SFCs towards the promotion of organic food and healthy eating at schools. Second, it investigated how the schools intend to create an environment which encourages and enables children to eat healthier. Third, the study looked at any actions undertaken by the schools to support such attitudes and intentions. Based on an in-depth analysis of the survey findings, a number of indicators were picked up for further data analysis in order to discover potential associations between the introduction of organic food and the provision of conditions that might be supportive of children's healthier eating at school.

\section{Instruments}

The initial questionnaire was designed in a Word format in English and later translated into German, Finnish and Italian respectively by the iPOPY partners in each country. As the aim was to compare the differences in school meals between organic and non-organic schools from three countries, the phrasing of the questions in the WBQ was adapted slightly in order to capture structural differences in the school food culture between Germany, Finland and Italy, although the subjects remained the same. In each country, the WBQ was pre-tested by experts. In Germany, the pilot test was not able to be carried out in schools, due to the difficulties in contact with the local authority. In Finland and Italy, the pilot tests were conducted in organic and non-organic schools. After all responses were collected, the iPOPY partners subsequently revised the questionnaire and produced the final version in the three languages. The completed questionnaires were converted to the web-based versions using the software SurveyXact. The WBQ were made available for respondents through a web browser link.

\section{School food coordinators' attitudes towards promotion of organic food and towards promotion of healthy eating habits}

In this section, the questions were aimed at mapping the attitudes and opinions of SFCs concerning school responsibility towards the promotion of organic food and healthy diets through food serving and education. The statements 
addressing attitude were: 'I think that the school has a responsibility in promoting healthy eating habits through its food service' and 'I think that school has a responsibility in promoting healthy eating habits through its curricular activities'. There were six response categories ranging from 'strongly agree' to 'strongly disagree'. By not providing a neutral scale (e.g. 'neither agree nor disagree'), this forces respondents to think about each scale and answer the response categories provided, rather than respondents repeatedly choosing the same answer to each questions ${ }^{(30)}$.

\section{Schools' intentions in serving healthy school meals and} creating a bealth-promoting school

To explore the schools' intentions concerning the promotion of healthy eating habits among children through offering organic and healthy school meals, proxy measures in relation to mapping school health policies were taken. For example, 'Does your school have a Food and Nutrition Policy (FNP) in relation to pupils' health?', 'Do teachers involve this FNP during teaching activities?' and 'Does your school have a health-promoting school policy according to WHO principles?'. It was also asked whether the school had a policy to purchase organic products, and this indicator was used to categorize the sampling schools into two groups; organic and non-organic schools. These questions were dichotomized as having answered 'yes' $v$. 'no'.

\section{Actions that schools had undertaken towards bealthy school meals}

SFCs were asked questions that addressed the school food system in practice, including whether the schools offered a school canteen with a dining hall, suggestions for children to choose healthier meals and the provision of nutritious school meals. The questions used were: 'Does your school have a canteen?', 'Does your school recommend its own nutritional menus for pupils in the canteen?' and 'Is the school food nutritionally calculated according to official nutritional guidelines?'. These questions were dichotomized as having answered 'yes' $v$. 'no'.

\section{Procedures}

\section{Germany: a market-oriented model}

In Germany, limited resources and ethical considerations regarding the handling of the schools' contact information meant that the study was limited to the state of Hesse. The selected schools were invited to participate in the WBQ via a link inserted into the monthly school newsletter made by the Ministry of Education and Cultural Affairs in Hesse. The newsletters were attached with the link to the WBQ and in November 2009 a short text about the project was distributed to all schools ( $n$ 2050) in Hesse. The WBQ was open for completion from November 2009 to April 2010. To increase the response rate, the link was also put on the website of the School Coordinator Centre in Hesse, although no reminder was sent.
Finland: a public welfare system model

Two nutrition researchers helped with the collection of Finnish school contacts: one from South Savo Vocational College, who provided email addresses of 143 schools, as well as a nutrition researcher from Laurea Polytechnic, who offered 855 school contacts. The WBQ was subsequently distributed to 988 schools along with a brief introduction about the project. Two reminders were sent out one and two weeks after initial distribution. The questionnaire was open for about a month from November to December 2009.

\section{Italy: a mix model of citizenship and market-oriented model}

In Italy, the lists of school contacts were obtained from iPOPY research partners in Milan. The selected 940 schools were distributed in eight provinces: Bergamo ( $n$ 146), Bologna ( $n$ 130), Brescia ( $n$ 170), Cremona ( $n$ 16), Lecco ( $n$ 21), Milano ( $n$ 268), Pavia $(n 72)$ and Varese ( $n$ 117). The WBQ, distribution letter and three reminders were translated into Italian. The WBQ was open for two months from December 2009 to February 2010. To increase the response rates three reminders were sent after sending the WBQ. The link to the WBQ was provided in the email each time.

\section{Statistical analysis}

All statistical analyses were carried out using the statistical software package IBM SPSS Statistics version $19 \cdot 0$. Only completed questionnaires were retained for analysis. Descriptive statistics were first used to measure the frequency of the variables studied. All $P$ values reported were two-tailed. The level of significance used was $P<0 \cdot 05$. The independent variables were country (Germany, Finland and Italy) and school category (organic and non-organic).

The factorability of the attitude questions was examined by principal component analysis, because the primary purpose was to identify and compute composite scores for the factors underlying the attitudes of the SFCs. First, all four items - namely, (i) attitude towards promotion of organic food via school food service; (ii) attitude towards promotion of organic food via teaching activities; (iii) attitude towards promotion of healthy eating habits via school food service; and (iv) attitude towards promotion of healthy eating habits via teaching activities - were correlated with two components, suggesting reasonable factorability. Second, at $0 \cdot 51$, the Kaiser-Meyer-Olkin (KMO) measure of sampling adequacy, testing whether the partial correlations among variables are small, indicated it was acceptable for factor analysis to proceed ${ }^{(31)}$ and Bartlett's test of sphericity, testing whether the correlation matrix is an identity matrix, was significant in our study $\left(\chi^{2}(6)=440 \cdot 53, P<0 \cdot 001\right)$. Finally, the communalities were all above 0.5 (see Table 2), further confirming that each item shared some common variance with other items ${ }^{(31)}$. Thereafter, the Kruskal-Wallis test was used to test comparisons of independent variables. This was due to the fact that attitude questions included ordinal 
values, and there were also two independent variables. In addition to this, the Kruskal-Wallis test is a non-parametric test that does not assume normality in the data, so was therefore appropriate for the present study ${ }^{(31)}$.

For the questions regarding intentions and action, the dependent variables were nominal. Logistic and multinomial regression analyses were used to examine the association between dependent and independent variables. To obtain the odds ratio, a confidence interval of $95 \%$ was used. The Hosmer and Lemeshow goodness-of-fit test from logistic and multinomial regression was used to examine whether the estimated model fit the data at an acceptable level ${ }^{(32)}$. In the form of an odds ratio, the comparison between each independent variable was estimated, with Germany and non-organic schools used constantly in logistic and multinomial regression models as the reference categories.

\section{Results}

Table 1 shows the number of questionnaires distributed, the number of organic and non-organic schools and the respondent rate from Germany, Finland and Italy. Among the respondents, only $12 \%$ of German, $10 \%$ of Finnish and $25 \%$ of Italian schools were classified as organic schools according to the definition in the WBQ.

\section{Attitudes}

We first investigated the SFCs' attitudes towards the promotion of organic food and healthy eating habits through school food services and teaching activities in the organic and non-organic schools in each country. Overall, the factor analyses in Table 2 indicate that there were two distinct underlying factors to the SFCs' responses to the questions on attitudes. Factor 1 was labelled 'sustainable reasons to determine SCFs' attitude' due to the high loadings on the following item: to promote organic food via school food service and teaching activity. This first factor explained $49.45 \%$ of the variance. The second factor derived was labelled 'health reasons to determine SCFs' attitude' due to the high loadings on the following factors: to promote healthy eating habits via the school food service and

Table 1 Number of questionnaires distributed, number of organic and non-organic schools and response rates in Germany, Finland and Italy; iPOPY study, November 2009 to April 2010

\begin{tabular}{lrrr}
\hline & Germany & Finland & Italy \\
\hline Distributed $(n)$ & 2050 & 998 & 940 \\
Responded $(n)$ & 122 & 250 & 215 \\
Organic schools $(n)$ & 14 & 24 & 53 \\
Non-organic schools $(n)$ & 44 & 69 & 108 \\
Don't know $(n)$ & 5 & 8 & 26 \\
Missing values $(n)$ & 59 & 149 & 28 \\
Respondent rate $(\%)$ & 6 & 25 & 23 \\
\hline
\end{tabular}

iPOPY, innovative Public Organic food Procurement for Youth.

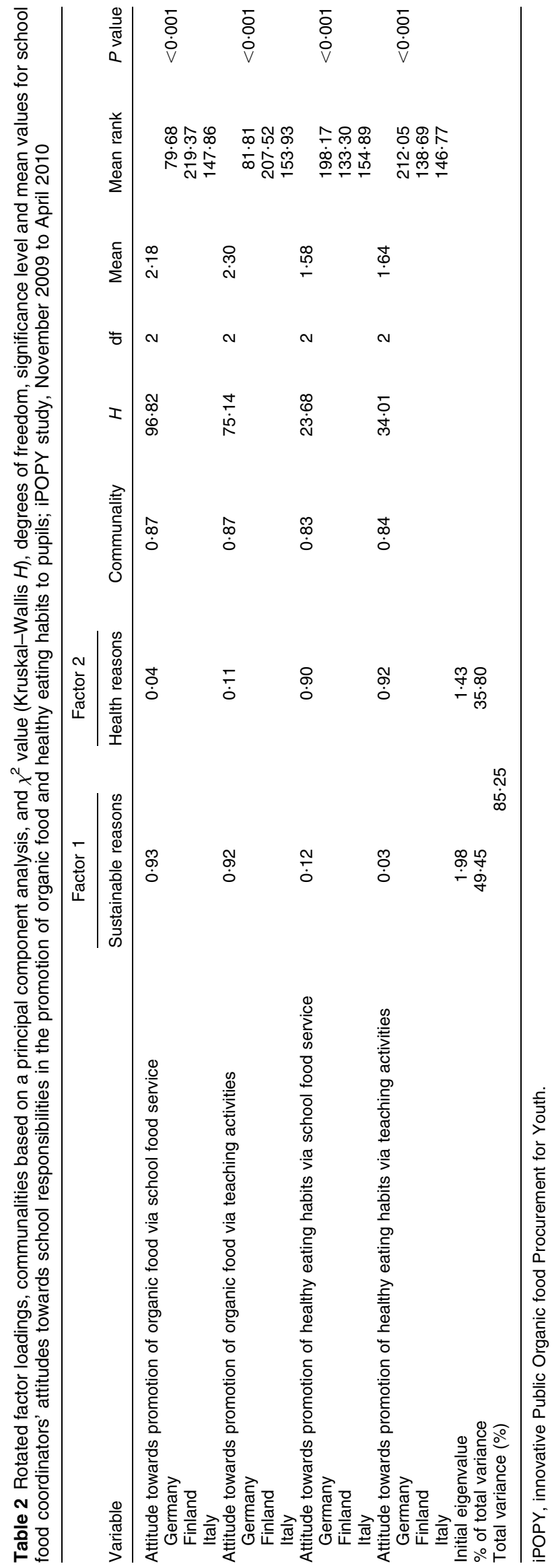


teaching activities. The variance explained by this factor was $35 \cdot 80 \%$.

The communalities of the variables included were over $50 \%$, so that they rated high overall. This suggests that the variables chosen for this analysis were related to each other. Furthermore, the KMO test and Bartlett's test of sphericity indicated that the set of variables were adequately related for factor analysis. Subsequently, this means that we have identified two clear patterns of response among SFCs: the promotion of organic food through school food services and teaching activities for sustainable reasons (or not); and the promotion of healthy eating habits through school food services and teaching activities for health reasons (or not).

The Kruskal-Wallis test results presented in Table 2 also reveal significant between-country effects for all four attitudes included in the analysis. In addition to this, results shown in Table 2 suggest that a positive attitude towards the promotion of organic food at school was most apparent in the Finnish schools and Italian schools ranked second place. The promotion of healthy eating habits at school was most common in German schools and Italian schools ranked second place again. In all cases, the organic and non-organic schools ranked almost evenly on the positive side of the scale, suggesting that they both perceive the role of the school as key in the promotion of organic food and healthy eating. Due to the coherence of this distribution, the relationship between the type of school (organic or non-organic) and the SFCs' attitude was not statistically significant.

\section{Intentions}

Table 3 shows the odds ratios for both types of school in the three countries to have an FNP and involve such a policy in the school's pedagogic activities. The Hosmer and Lemeshow goodness-of-fit tests showed no difference between the estimate and the raw data, which means that the model represented the data at an acceptable level. In the logistic regression, the Finnish schools were most likely to adopt an FNP at school of the three countries $(P<0 \cdot 001)$. The results also show that the non-organic schools were $0 \cdot 14$ times less likely to have an FNP than the organic schools in all countries $(P<0 \cdot 001)$. In this section of the WBQ, the schools' respondents were also asked whether their schools involved FNP issues in their pedagogic activities. Table 3 shows that the Italian schools were most likely to involve the FNP in their teaching activities compared with the German schools $(P=0 \cdot 004)$. No significant results were obtained for FNP in education in Finland.

Table 4 shows the binary logistic regression analysis results for each country regarding the adoption of a WHO health-promoting school policy, possession of a playground and involvement of physical activity as a prioritized theme in curriculum activity. The Finnish schools were most likely to adopt a health-promoting school policy

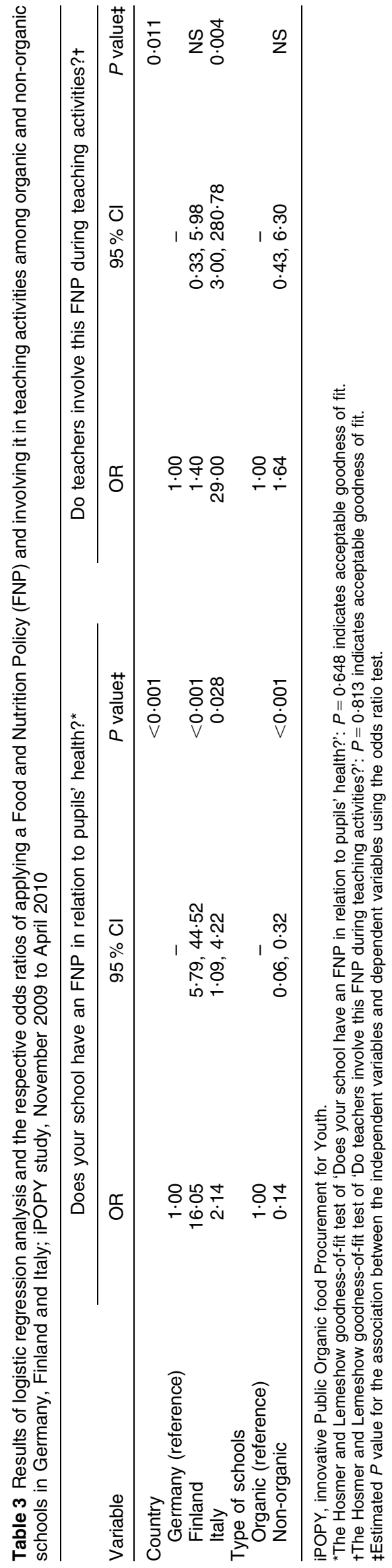


according to WHO principles $(P<0 \cdot 001)$. The non-organic schools were $0 \cdot 18$ times less likely to adopt this policy compared with the organic schools $(P=0 \cdot 002)$. The Finnish schools were ranked first in terms of the possession of a school playground and the involvement of physical activity as a prioritized theme in curriculum activity, not including a gym course. However, no associations between having a playground, the involvement of physical activity as a theme in teaching activity and the type of school were detected.

\section{Actions}

Table 5 shows the logistic regression analysis results concerning the existence of a school canteen, the operation of nutritionally calculated menus and the enforcement of nutritional recommendations for children, among organic and non-organic schools in Germany, Finland and Italy. The results indicate that the Finnish schools were most likely to have a canteen $(P=0 \cdot 001)$. The existence of a school canteen facility was also associated with the type of school, being more likely in the organic schools $(P=0 \cdot 017)$. The Italian schools were most likely to serve nutritionally calculated meals $(P<0 \cdot 001)$ and to recommend the pupils to choose healthier foods $(P<0 \cdot 001)$ among all of the countries. No associations between school type and the operating of nutritionally calculated menus, or the enforcement of nutritional recommendations for children, were found.

\section{Discussion}

To the authors' best knowledge, the present study is one of the first examining the impact of organic food sourcing strategies on the shaping of healthier school food environments. The study was carried out as part of the iPOPY project, which conducted a pioneering investigation into the relationship between school food policy and consumption of organic meals in three EU countries ${ }^{(4)}$.

The present study showed that SFCs in all cases have a supportive attitude towards promoting organic food and health for children through the school setting, independently of whether their school was classified as organic or non-organic. Specifically, SFCs in the Finnish schools were more likely than SFCs in other countries to agree about the responsibility of the school to promote organic food consumption. On the other hand, SFCs in the German schools were more likely to agree with the promotion of healthy eating habits, both through school food services and through curricular activities. Nevertheless, SFCs' attitudes regarding promotion of organic foods and healthy eating habits at school may be independent of organic introductions. Their attitudes could be influenced by physical environments, national or traditional school food practices, etc. Although SFCs have great enthusiasm for promotion of healthy school food service, the school 
systems in these three countries are publicly administered by a higher level such as local municipality, and the power of SFCs to achieve their ambitions is challenging because of their subservient positions at school.

In Finland, organic schools were more engaged in adopting or maintaining an FNP and a health-promoting school policy according to WHO principles (http:// www.who.int/school_youth_health/gshi/hps/en/index.html) than the non-organic schools. Furthermore, of all three countries, it was the Finnish schools that had the most concern about the provision of playgrounds and the involvement of physical activity as a prioritized theme in teaching for children. First, these findings could be attributed to the fact that the organic schools in Finland have more motivation and concern for the implementation of school health policies. Second, this could also be due to the long tradition of public involvement in Finnish school routines ${ }^{(3,21,22,32)}$. In Finland, the municipality decides policies determining the types of food products contained in school meals, while the composition and nutritional values of the school food are controlled by both the municipality and the catering companies ${ }^{(3,21,22,32)}$. In addition to this, the health authorities also need to approve the menus that will be offered to pupils ${ }^{(32)}$. Third, Finland participated in the European Network of Health Promoting Schools (ENHPS) project in the 1990s, which aims to promote the health of pupils and school staff by developing school social and physical environments ${ }^{(33)}$. This project may have positively influenced the Finnish schools and such impacts may have been maintained to the present day.

Previous studies by Morgan and Sonnino show that, from 2008, the Italian municipalities, especially in Northern provinces, put more effort into the development of healthy and nutritious school meals, complemented with educational programmes ${ }^{(27)}$. The school teachers therefore became responsible for integrating these nutrition issues into teaching activities ${ }^{(27,34)}$. The present study confirms the observation that the Italian SFCs had most concern regarding integrating FNP issues into teaching activities. Previous studies also found that the school food environment is an important venue for children to practise healthy eating. This may be through the types of food made available in school and through educational messages delivered by the school to facilitate making healthy food choices, as specified in school food policies ${ }^{(35-37)}$.

Our third result suggests that the Finnish organic schools were most likely to provide a school canteen than the non-organic schools. However, according to The Basic Education Act (628/1998) in Finland, all schools have an obligation to provide a canteen ${ }^{(32)}$. Catering at Finnish school canteens is provided on a self-service basis with personal supervision ${ }^{(32)}$. Perhaps more importantly, the canteen also provides an opportunity for schools to promote health and well-being ${ }^{(38,39)}$. Previous studies suggest that improving the nutritional value of school meals for children may positively influence their dietary intake ${ }^{(40-43)}$. 
Regarding calculation of the nutritional content of school meals, the Italian schools reported maintaining routines for these calculations, as well as recommending healthier food choices to children. Our results are in agreement with reports from another parallel study in the iPOPY project $^{(3,34)}$, which has also shown that healthy school food is much more a priority in Italy, with Italian authorities currently more focused on the quality of school meals than ever ${ }^{(3,34)}$.

A limitation of the present study is its cross-sectional nature that does not allow us to infer causality. However, the study provides a snapshot of the present situation in the studied countries and allows for comparisons within and between countries. There were some logistic differences in the execution of the survey in the different countries, particularly the reminders sent and the duration of the web-based surveys ${ }^{(43)}$. Although this might be a source of bias, we believe that the sample size overcomes the presence of differences that would be due to chance. In addition to this, the effect size of the study sample has been checked and it detected the small effect. For example, the effect size of fourteen organic schools and forty-four nonorganic schools in Germany is an absolute Cohen's $d$ of $0 \cdot 28$, so we can assume a small effect. Second, administering the survey online was limited in that not all school staff have access to the Internet, and variations in familiarity with computer technology and literacy may also have produced bias. Therefore, we avoided asking questions which contained complex terms and words, or asking for the respondent's overall opinion of the school food system, instead asking more specific questions ${ }^{(44,45)}$. However, for online surveys it is not possible to completely avoid sample selection bias where we had no control over who actually responded $^{(44,45)}$. We therefore designed the questionnaire as consisting of open-ended questions and encouraging respondents to provide their feedback, in order to minimize response bias (i.e. participants answering the way they think they should answer ${ }^{(44,45)}$ ).

\section{Conclusions}

The present study identified some positive associations between type of school (organic or non-organic) and the provision of a healthful school-food environment. Having an FNP can be one of many sustainable actions to promote a healthy school-food environment for children. The SFCs from organic and non-organic schools had positive attitudes concerning the promotion of organic food and health within the school context, but they need to work with other actors to achieve the aim. Schools classified as 'organic' in the studied countries were more likely than non-organic schools to adopt the FNP and, in Finland, to apply a school health-promoting policy according to WHO principles and to facilitate a school canteen. Moreover, Finnish schools expressed the most positive attitudes towards schools having a playground and the teaching of physical activity as a prioritized theme for children. However, these positive indications may be dependent on well-developed national legislations behind the Finnish school system. Italian schools were most positive towards involving the FNP issues in educational activities, serving nutritious school meals and recommending schoolchildren to choose healthier foods. This might also be due to the long traditional Italian school food system. All in all, the present study has found that there is still a large evidence gap on the effects of public organic food procurement policy on eating behaviours.

\section{Acknowledgements}

Sources of funding: This work was supported by the Danish Food Industry Agency. This work belonged to the CORE Organic Funding Body Network for the transnational funding of the CORE Research Pilot Project, 'Innovative Public Organic food Procurement for Youth' (iPOPY). Conflicts of interest: No conflicts of interest exist for the authors. Ethics: Ethical approval was not required in this study. Authors' contributions: C.H. was responsible for data collection, analysis of results, writing the draft for the manuscript and finalizing the manuscript. F.J.A.P.-C. was responsible for analysis of results, comments on the draft of the manuscript and participated in structuring the manuscript. B.E.M. was responsible for comments on the draft of the manuscript and participated in structuring the manuscript. Acknowledgements: The present research was conducted in the participating countries in the iPOPY project: Germany, Finland and Italy. The authors wish to express thanks to Carola Strassner and Melanie Lukas for their assistance and support during the conduction of the survey in Germany. Thanks also go to Minna Mikkola for her cooperation when performing the survey in Finland, and to Marco Valerio and Roberto Spigarolo for their help and contributions to carrying out the survey in Italy.

\section{References}

1. Morgan K \& Sonnino R (2008) A sustainable world city? School food reform in London. In The School Food Revolution: Public Food and the Challenge of Sustainable Development, pp. 89-112. London: Earthscan.

2. Morgan K \& Sonnino R (2007) Empowering consumers: the creative procurement of school meals in Italy and the UK. Int J Consum Stud 31, 19-25.

3. Nielsen T, Nölting B, Kristensen NH et al. (2009) A comparative study of the implementation of organic food in school meal systems in four European countries. Bioforsk Report 4, no. 145, 27-32.

4. Løes AK \& Nölting B (2009) Organic school meal systems towards a more sustainable nutrition. Agron Res 7, 647-653.

5. Nölting B, Løes AK \& Strassner C (2009) Constellations of public organic food procurement for youth - an interdisciplinary analytical tool. Bioforsk Report 4, no. 7, 9-12.

6. Jones M, Dailami N, Weitkamp E et al. (2012) Food sustainability education as a route to healthier eating: 
evaluation of a multi-component school programme in English primary schools. Health Educ Res 27, 448-458.

7. Mikkola M (2010) Role of public catering and use of organic food in educational contexts: creating centres for sustainable food systems. Bioforsk Report 5, no. 104, 5-22.

8. Friedman WJ (2005) The framework for global organic food trade circa 2005: accomplishments and challenges. Food Drug Law J 60, 361-373.

9. Jaime PC \& Lock K (2009) Do school based food and nutrition policies improve diet and reduce obesity? Prev Med 48, 45-53.

10. Gharib N \& Rasheed P (2011) Energy and macronutrient intake and dietary pattern among school children in Bahrain: a cross-sectional study. Nutr J 10, 62.

11. Krolner R, Rasmussen M \& Brug J (2011) Determinants of fruit and vegetable consumption among children and adolescents: a review of the literature. Part II: qualitative studies. Int J Behav Nutr Phys Act 8, 112.

12. Nathan N, Wolfenden L, Butler M et al. (2011) Vegetable and fruit breaks in Australian primary schools: prevalence, attitudes, barriers and implementation strategies. Health Educ Res 26, 722-731.

13. Story M, Kaphingst KM \& French S (2006) The role of schools in obesity prevention. Future Child 16, 109-142.

14. Cooke L (2007) The importance of exposure for healthy eating in childhood: a review. J Hum Nutr Diet 20, 294-301.

15. Neumark-Sztainer D, French SA \& Hannan PJ (2005) School lunch and snacking patterns among high school students: associations with school food environment and policies. Int J Behav Nutr Phys Act 2, 14.

16. Friel S, Kelleher C, Campbell P et al. (1999) Evaluation of the Nutrition Education at Primary School (NEAPS) programme. Public Health Nutr 2, 549-555.

17. Vereecken CA, Bobelijn K \& Maes L (2005) School food policy at primary and secondary schools in Belgium-Flanders: does it influence young people's food habits? Eur J Clin Nutr 59, 271-277.

18. Kain J, Uauy R, Albala et al. (2004) School-based obesity prevention in Chilean primary school children: methodology and evaluation of a controlled study. Int J Obes Relat Metab Disord 28, 483-493.

19. Hoppu U, Lehtisalo J, Tapanainen H et al. (2010) Dietary habits and nutrient intake of Finnish adolescents. Public Health Nutr 13, 965-972.

20. Samuelson G (2000) Dietary habits and nutritional status in adolescents over Europe. An overview of current studies in the Nordic countries. Eur J Clin Nutr 54, Suppl.1, S21-S28.

21. Tilles-Tirkkonen T, Pentikainen S, Lappi J et al. (2011) The quality of school lunch consumed reflects overall eating patterns in 11-16-year-old schoolchildren in Finland. Public Health Nutr 14, 2092-2098.

22. Haapalahti M, Mykkanen H, Tikkanen S et al. (2003) Meal patterns and food use in 10- to 11-year-old Finnish children. Public Health Nutr 6, 365-370.

23. Katja R, Paivi AK, Marja-Terttu T et al. (2002) Relationships among adolescent subjective well-being, health behavior, and school satisfaction. $J$ Sch Health 72, 243-249.

24. Loss J \& Leitzmann M (2011) Environmental approaches in the prevention of obesity in children and adolescents. Bundesgesundheitsblatt Gesundheitsforschung Gesundheitsschutz 54, 281-289.

25. Huybrechts I, De Bourdeaudhuij I, Buck C et al. (2010) Environmental factors. Opportunities and barriers for physical activity and healthy eating among children and adolescents. Bundesgesundheitsblatt Gesundheitsforschung Gesundheitsschutz 53, 716-724.
26. Therre P, Knoll M \& Riemer-Hommel P (2012) School meals at secondary schools: an analysis in the District of St. Wendel in the Province Saarland, Germany. Gesundheitswesen $\mathbf{7 4}$, $467-475$.

27. Morgan K \& Sonnino R (2008) School food as social justice: the quality revolution in Rome. In The School Food Revolution: Public Food and the Challenge of Sustainable Development, pp. 65-88. London: Earthscan.

28. Godin G \& Kok G (1996) The theory of planned behavior: a review of its applications to health-related behaviors. Am J Health Promot 11, 87-98.

29. Ajzen I (1991) The theory of planned behavior. Organ Behav Hum Decis Process 50, 179-211.

30. de Leeuw ED, Hox JJ \& Dillman DA (2008) International Handbook of Survey Methodology. New York: Psychology Press.

31. Hosmer DW \& Lemeshow S (1989) Applied Logistic Regression. New York: John Wiley \& Sons, Inc.

32. Mikkola M (2008) Organic and conventional public food procurement for youth in Finland. Bioforsk Report 3, no. $41,13-17$

33. Turunen H, Tossavainen K, Jakonen $S$ et al. (1999) Initial results from the European Network of Health Promoting Schools program on development of health education in Finland. J Sch Health 69, 387-391.

34. Spigarolo R, Sarti MV \& Giorgi G (2010) Organic and conventional public food procurement for youth in Italy. Bioforsk Report 5, no. 109, 6-18.

35. Fung C, Kuhle S, Lu C et al. (2012) From 'best practice' to 'next practice': the effectiveness of school-based health promotion in improving healthy eating and physical activity and preventing childhood obesity. Int J Behav Nutr Phys Act 9, 27.

36. Harrison F, Jennings A, Jones A et al. (2011) Food and drink consumption at school lunchtime: the impact of lunch type and contribution to overall intake in British 9-10-year-old children. Public Health Nutr (Epublication ahead of print version).

37. Kim K, Hong SA, Yun SH et al. (2012) The effect of a healthy school tuck shop program on the access of students to healthy foods. Nutr Res Pract 6, 138-145.

38. Wouters EJ, Larsen JK, Kremers SP et al. (2010) Peer influence on snacking behavior in adolescence. Appetite 55, 11-17.

39. Lachat CK, Verstraeten R, De Meulenaer B et al. (2009) Availability of free fruits and vegetables at canteen lunch improves lunch and daily nutritional profiles: a randomised controlled trial. Br J Nutr 102, 1030-1037.

40. Bevans KB, Sanchez B, Teneralli R et al. (2011) Children's eating behavior: the importance of nutrition standards for foods in schools. J Sch Health 81, 424-429.

41. Briefel RR, Wilson A \& Gleason PM (2009) Consumption of low-nutrient, energy-dense foods and beverages at school, home, and other locations among school lunch participants and non participants. J Am Diet Assoc 109, 2 Suppl., S79-S90.

42. Story M, Nanney MS \& Schwartz MB (2009) Schools and obesity prevention: creating school environments and policies to promote healthy eating and physical activity. Milbank Q 87, 71-100.

43. Braithwaite D, Emery J, De Lusignan S et al. (2003) Using the internet to conduct surveys of health professionals: a valid alternative? Fam Pract 20, 545-551.

44. Johnson TP \& Wislar JS (2012) Response rates and non response errors in surveys. JAMA 307, 1805-1806.

45. Plante C, Jacques L, Chevalier S et al. (2012) Comparability of Internet and telephone data in a survey on the respiratory health of children. Can Respir J 19, 13-18. 